\title{
Beyond COVID-19: Creating a public health system based on Comprehensive Primary Health Care
}

\author{
Susan Rifkin ${ }^{1}$, Tashi Tobgay ${ }^{2}$ \\ ${ }^{1}$ Colorado School of Public Health \\ ${ }^{2}$ Institute of Health Partners
}

The World Health Organization was created in 1948. It was initially focused on medical and bio-medical issues and on the delivery of health services. The Alma Ata Declaration of 1978 brought the wider context of social determinants based on the principles of equity and community participation into discussions about how health improves ${ }^{1}$. The Global Conference on Primary Health Care in Astana, Kazakhstan in October 2018, reinforced the critical role of primary health care to ensure that everyone everywhere is able to enjoy the highest possible attainable standard of health ${ }^{2}$. Primary Health Care (PHC) became the policy of all member nations. Despite this policy, focus has remained on the delivery of health services. This siloed approach proved inadequate to address the COVID pandemic. The result has been the loss of several hundred thousand lives as well as livelihood of millions more people ${ }^{3}$.

A recent publication from the Organization for Economic Cooperation and Development (OECD) entitled "Realizing the potential of Primary Health Care" reviewed the experience of the early response to the COVID-19 epidemic in member countries ${ }^{4}$. The report examines the weaknesses of existing public health systems and highlights options for critical improvements to meet not only future epidemics but to immediately reform of the existing systems. Its key messages are: 1) the necessity of building multiservice health teams (rather than individual medical professionals) who provide their specific skills supported by digital technology and are pro-active in preventive work tailored to specific populations 2) the need to give economic incentives to health workers to provide preventive and continuous care to chronic patients as population shifts to people living longer and ensure the transition of this care as necessary 3) a broader role for patients in their own health care by self- management of their health conditions and attention to risky behavior and a stronger community input to health care provision as the local level 4)

Corresponding author:

Tashi Tobgay

tobgayla2000@gmail.com the recognition that Universal Health Coverage (UHC) is not only financing health care. It also needs to address the social determinants that cause poor health and strengthen prevention. Primary Health Care is not only the provision of health services. Health service provision must be integrated into the wider framework of the social determinants of health through a strong public health system. There are lessons from OECD countries that have integrated health services into comprehensive Primary Health Care. These lessons highlight two critical factors for a successful transition to a post COVID public health system. The first is that context is important. While a specific medical intervention has proven effect, public acceptance depends of how the public perceives the intervention as addressing their needs and concerns. The second is that improvements to the health status of population is a process that develops over a number of years with acceptance and behavioral changes in populations that depend on how credible those who present new policies are perceived. These lessons can be applied to the Bhutanese context in planning the future health care system.

Bhutan has always espoused primary health care health delivery system as the main approach to health care services. Bhutan started its path to modern health care system in 1970s. With the establishment of the Royal Institute of Health Sciences (currently known as Faculty of Nursing and Public Health) in 1974, the Primary Health Care system was well grounded with continuous supply of primary health care workforce. The paramedical graduates (Health Assistants and Nurses) from the institute was posted across the country and became the backbone of the primary health care services in Bhutan ${ }^{5}$. Since then, Bhutan saw a steady growth in health indicators. Average life expectancy reached to 70.2 years, child immunization coverage was sustained above $95 \%$ and household out-of-pocket expenditure was kept very low ${ }^{6}$. Bhutan has no private hospital and all health services including hospitalizations, medicines, diagnostics and even referrals to India are provided by the State as a constitutional right to citizens.

While, Bhutan saw a steady progress, it is far from adequate to address the current challenges and move beyond pandemics. The pandemics validated the importance for the need of qualified and skilled frontline health workers. Bhutan is in dire shortage 
of health workers particularly medical doctors, intensive care nurses and technicians. Country also saw an increasing burden of noncommunicable diseases. The Bhutan STEPS survey 2019 revealed a growing burden of Non-communicable diseases. The survey showed prevalence of raised blood pressure $(28 \%)$, raised blood sugar (1.9\%), raised cholesterol (11\%), obsessed with BMI greater or equal to $30 \mathrm{~kg} / \mathrm{m} 2$ (11.4\%) with $3.7 \%$ aged $40-69$ years with 10 years CVD risk greater than or equal to $30 \%^{7}$. Despite progress, the growing burden of non-communicable diseases coupled with high burden of infectious diseases and pandemics, Bhutan faces a significant health service delivery challenge. In this syndemic era, country needs to realign and re-orientation of the current health care delivery to make it a people centred approach with better community engagement and to equip it with better diagnostic and treatment facilities along with competent and qualified health workforce. The districts health needs extensive support not only to tackle increasing NCD burden but also growing infectious diseases of epidemic in nature. One health approaches in tackling infectious diseases of zoonotic origin could be applied. Further, greater use of information technology may be adopted both at central and districts level for planning and health service delivery to the people.

\section{REFERENCES}

1. World Health Organization. WHO/Europe | Publications Declaration of Alma-Ata, 1978 [Internet]. 1978 [cited 2020 Oct 20]. [Full Text]

2. Walraven G. The 2018 Astana Declaration on primary health care, is it useful? J Glob Health [Internet]. 2019 [cited 2020 Oct 20];9(1):10313. [Full Text]
3. Loewenson R, Accoe K, Bajpai N, Buse K, Deivanayagam TA, London L, et al. Reclaiming comprehensive public health. BMJ Glob Heal [Internet]. 2020 Sep 1 [cited 2020 Oct 20];5(9):e003886. [Full Text]

4. OECD. Realising the Potential of Primary Health Care, OECD Health Policy Studies, [Internet]. Paris: OECD Publishing,; 2020 [cited 2020 Oct 20]. (OECD Health Policy Studies).

5. Tobgay T, Yangchen S, Wangchuk U, Lhendup S, Jurmin $\mathrm{K}$, Anjana Pradhan W, et al. Improving retention of health workers in rural and remote areas: Case studies from WHO South-East Asia Region. 2019.

6. Gurung MS, Dorji G, Khetrapal S, Ra S, Babu GR, Krishnamurthy RS. Transforming health care through Bhutan's digital health strategy: progress to date [Internet]. Vol. 8, WHO South-East Asia journal of public health. NLM (Medline); 2019 [cited 2020 Oct 18]. p. 77-82. [Full Text]

7. Department of Public Health. Noncommunicable risk factors, Bhutan STEPS survey 2019. Thimphu; 2020. 